(C) 2006 The Author

Journal compilation (C) 2006 Metaphilosophy LLC and Blackwell Publishing Ltd

Published by Blackwell Publishing Ltd, 9600 Garsington Road, Oxford OX4 2DQ, UK, and

350 Main Street, Malden, MA 02148, USA

METAPHILOSOPHY

Vol. 37, Nos. 3-4, July 2006

0026-1068

\title{
COLLECTIVE ACTION AND THE PECULIAR EVIL OF GENOCIDE
}

\author{
BILL WRINGE
}

\begin{abstract}
There is a common intuition that genocide is qualitatively distinct from, and much worse than, mass murder. If we concentrate on the most obvious differences between genocidal killing and other cases of mass murder it is difficult to see why this should be the case. I argue that many cases of genocide involve not merely individual evil but a form of collective action manifesting a collective evil will. It is this that explains the moral distinctiveness of genocide. My view contrasts with one put forward by Claudia Card, though we both agree that the notion of "social death" plays a significant role here.
\end{abstract}

Keywords: genocide, evil, collective action.

\section{Introduction}

It is widely believed that there are significant moral differences between mass murder, on the one hand, and genocidal killing, on the other. While both are horrifying, the latter evokes the peculiar revulsion that has resulted in genocidal acts being given a unique moral and legal status as "crimes against humanity." Although very few people would be willing to question that special status, it is not immediately obvious how it is to be explained. Putative explanations that look to the characters of the agents of genocide, to their intentions in committing genocide, or to the scope of the crime all seem to miss the mark.

This might lead one to question the intuition that genocidal killing does indeed have a peculiar moral status. One way of doing so would be to attempt to explain it away. In doing so, one might perhaps appeal to the special salience of morally significant events in relatively recent history, or to the pragmatic, consequentialist benefits of according genocidal crimes a peculiar status. However, whatever their merits, these ways of explaining away the intuition seem unable to do justice either to its force or to its structure.

In this essay I argue that we can explain at least some of our intuitions about the peculiar evil of genocide by paying particular attention to the ways in which genocidal killing involves collective action. It does so in a 
way that distinguishes genocides from other sorts of mass murder. The explanation I have in mind can be described as a "vindicatory explanation": it is supposed to explain the intuition in a way that enables us to continue to endorse it in a relatively straightforward manner, and not merely as an intuition that we should be glad we have, regardless of its truth, on (for example) indirect utilitarian grounds.

More specifically, I shall be claiming that this intuition represents a rational response to the callous attitudes expressed in the collective willing that is typically to be found in cases of genocidal killing, and in particular to the fact that the collective willing involves a deliberate, explicit and conscious lack of respect for the humanity of its victims. In arguing in this way, I shall be engaging at two points with important recent work by Claudia Card (2001, 2003).

Card has argued that accounts of evil which focus on the qualities of will that are embodied in evil action - as mine in effect does - are inadequate in so far as they lead us to neglect the significance of the suffering of victims of evil (Card 2001, esp. chaps. 1 and 4). Card has also proposed her own account of the peculiar evil of genocide. Central to her account is the idea that genocidal killing inflicts a particular kind of harm on victims, especially on survivors, which she refers to as "social death" (Card 2003).

My disagreements with Card focus on two main points. First, while I agree with her that an adequate analysis of evil needs to make appropriate reference to the suffering of victims of evil, I do not agree that any account of evil which locates evil in qualities of will need neglect such suffering. More narrowly, while I agree that some possible accounts of evil that locate evil in collective willing might be problematic in precisely this way (and I discuss one such account), I shall argue that my account accommodates - as Card says any adequate account should accommodate, and as her account aims to-reference to both the intentions of perpetrators and the suffering of victims.

Secondly, while I take the notion of social death to be an important analytical tool in understanding the evil of genocide, and I draw on it at a key stage of my argument for my own view, I do not think that the genuine dreadfulness of the harm that individuals who suffer social death undergo is sufficient to account for our intuitions about the peculiar status of genocide. Card's account of social death seems to leave open the possibility that in at least two sorts of case individuals might suffer social death without being the victims of genocide. These are cases in which the harm of social death is inflicted in ways that do not involve the destruction of a society or a way of life. While I take it that such cases would involve profound harm to individuals, and that the appropriate response to victims of such harms might have much in common with appropriate responses to victims of genocide, I shall argue that our response to the situations that bring them about is not, and should not be, identical to that evoked by genocidal killing. 


\section{A Puzzling, but Powerful, Intuition}

I have alluded several times to the existence of an intuition to the effect that genocidal killing has a peculiar moral status. It is now time to say something more about its content. The intuition I am discussing is that the fact that a class of killings can be correctly characterised as "genocidal killings" makes them significantly worse, from a moral point of view, than a similar quantity of killings that are non-genocidal but in other respects similar.

A few clarificatory remarks are in order here. I shall take it for granted, for present purposes, that the intuition about the special moral status of genocide that I refer to does exist and is fairly widely shared (though I leave open the question of exactly how widely shared it is). I take the existence of a special legal category of crimes against humanity to provide evidence, but not indefeasible evidence, for this claim. (To be clear: I don't take this as evidence that the intuition is true, only that it is widely shared. But, to forestall misunderstanding, I should probably state explicitly at this point that I don't have any doubt that it is true.)

One could take the legal recognition of this category of crime to be capable of explanation in ways that do not presuppose moral beliefs of any sort. Such modes of explanation are characteristic, for example, of doctrines that go by the name of "realism" in the field of international relations. However, although realist views of this sort might be capable of explaining how crimes against humanity have attained the status that they have within international law, it is much harder for them to explain why the recognition of this category of crime strikes so many people as such a significant moral achievement.

I shall also take it for granted that it is appropriate to look for an explanation of this intuition that vindicates it. This is not because I think that the intuition is one that is beyond all possibility of doubt: there could be circumstances in which one might have good epistemic grounds for doubting it (although I do not think that those possible circumstances are at all close to actual circumstances). Nor do I think that our entitlement to be confident in the truth of the intuition depends on our being able to provide a vindicatory explanation of it. ${ }^{1}$ Rather, I take it that the intuition is one that has (at least) a prima facie entitlement to be taken at face value, and that the task of explaining why it is true is a legitimate, and significant, philosophical task.

I shall be arguing that the peculiar evil of genocide is best explained by focusing on the idea that genocidal killings involve collective action, and

\footnotetext{
${ }^{1}$ I use the phrase "vindicatory explanation" here in a way slightly different from that pioneered by David Wiggins (Wiggins 1987). For Wiggins, a vindicatory explanation shows that "there is simply nothing else to think" about a certain subject matter. On my usage a vindicatory explanation explains a belief while at the same time showing that we are justified in holding it, but does not necessarily show that "there is nothing else to think."
} 
then appealing to the nature of that collective action to explain the sort of evil involved. However, before going any further, it may be worth making a brief observation about the generality and modal status of the claim that I am making about the connection between genocide and collective action. I shall not be claiming that every conceivable instance of genocide involves collective action. We might perhaps be able to imagine possible instances of genocidal killing that do not. The sorts of case I have in mind here are cases that involve small numbers of very destructive agents. For example, someone might dream up an example of a single individual armed with a nuclear weapon that he or she manages to fire at an island inhabited entirely by the members of a single ethnic or national group.

Fictional examples of this sort should not detain us for very long. ${ }^{2}$ When described in any detail, putative examples like this tend to fall into one of two categories: cases where collective action does turn out to be involved after all, and cases that are so far removed from the circumstances of the real world that there seems little reason to give much weight to any moral intuitions they might invoke. Consider the case of the individual with the nuclear weapon in more detail. Such weapons typically require a great deal in the way of maintenance, hardware support and software for guidance and targeting. Once we say something about these sorts of features of the situation it becomes much harder to deny that the firing of the weapon is likely to involve collective action. But if we set aside these features of the situation we find ourselves in the realm of morally irrelevant (and in this case morally offensive) science fiction. ${ }^{3}$

\section{Is the Intuition to Be Explained?}

At this point, it may be worth trying to pre-empt a significant sceptical response to what I shall be saying. This is to suggest, without denying either the truth or the force of the intuition in question here, that there is no explanation of it to be had. I shall introduce the line of thought I have in mind here in a slightly oblique manner.

It is sometimes suggested that there is something wrong about any attempt to explain the Holocaust. In doing so, it is said, one undermines its status as a uniquely evil event. Whether or not this line of thought is correct, it suggests something that one might take to be at odds with any attempt to give an explanation of what is peculiarly evil about genocide

\footnotetext{
${ }^{2}$ It bears emphasis that the objection is not to fictional examples as such but to that peculiar fictional genre, the philosophical example - typically, highly abstract and presented so briefly as to discourage reflection on the question of whether the examples could be filled out in a plausible and consistent manner without undermining the point that they have been employed to make.

${ }^{3}$ Some people might hold that it is a sign of a certain moral shallowness (perhaps characteristic of some forms of analytic moral philosophy) even to consider such cases. I sympathise with the charge, though I do not entirely endorse it.
} 
per se. For one might think that although every act of genocide is peculiarly evil, each instance of genocide is evil in its own particular way. In order to understand this evil we need to confront the particular details of particular instances of genocidal killing. We cannot do so by subsuming genocide under a general category and trying to explain what it is that makes events which fall into that category peculiarly evil. ${ }^{4}$

The only response to this line of thought that is likely to carry any weight is to provide a convincing general account of the peculiar evil of genocide - as I shall be trying to do. Still, it may be worth speaking to the unease that such an attempt may arouse by pointing out that there is no reason why one should not believe both that there is something distinctively evil about genocidal killing per se and that particular instances of genocide may themselves be peculiarly evil in further, more distinctive ways. Someone who believes this may also believe that these further, more particular evils can only be understood - if they can be understood at all-by confronting the concrete detail of particular cases.

\section{Genocide and Collective Action}

We are now in a position to consider in more detail the claim that genocidal killings involve a form of action that is distinctively collective. In talking of a form of action's being "distinctively collective," I mean to draw attention to something over and above the number of agents who are involved in it. So the claim that genocidal killing involves distinctively collective action is not simply equivalent to the fact that genocidal killing typically involves a large number of perpetrators, although that fact is, of course, relevant to my discussion.

I shall argue that the perpetrators of genocide act collectively (or act together-I shall use both phrases) in a sense in which organized groups and, possibly, less formally co-ordinated groups such as crowds can act together, but in which a set of randomly selected individuals whose actions do not impinge on one another cannot be said to act together. This sort of collective action has been illuminatingly discussed by a number of contemporary philosophers, including Margaret Gilbert (1989, 2000), Peter French (1984) and Christopher Kutz (2000a and 2000b). It is a sense in which two individuals can take a walk together; a group of friends can plan and undertake an outing; a corporation can make a third of its employees redundant; and so on. These are mundane examples, and I choose them for the sake of emphasizing that the sort of phenomenon that I have in mind is not meant to be something especially mysterious, even though, as I shall argue, its presence in the context I am discussing is not negligible either.

${ }^{4}$ For discussion of various generalizing accounts of the Holocaust see Roth 2004. 
Authors who have discussed collective action have differed on a number of issues. Among these issues is the question of the sorts of metaphysical implications that our talk of collective action might have. For Gilbert and French it commits us to taking seriously the existence of collective subjects or collective agents. For others it does not. On this second sort of approach, talk about collective agency should be understood as being talk about individuals acting collectively, not as talk about the actions of collectives.

I shall be relying on an account of collective action of the second sort-Kutz's recently developed "minimalist" account of collective action (Kutz 2000a and 2000b). On Kutz's account, collective action involves a group of individuals acting with what he calls "participatory intentions." An individual who has participatory intentions does what he or she does while intending his or her action to constitute a contribution to a collective project.

One important corollary of this account is that although an individual who is engaged in collective action needs to have some sort of conception of the joint project that he or she is engaged in, he or she need not be aware of who the other participants in the project are or what their roles might be. For such awareness is not a precondition of forming the relevant sorts of participatory intention. Consequently, the account is well able to accommodate cases of collective action that are not centrally co-ordinated and do not involve a significant degree of mutual self-recognition on the part of participants. (This is not, of course, to deny that central coordination can contribute to the success of collective action in many cases.)

As Kutz points out, many criminal conspiracies fit this characterisation: they are set up in such a way as to ensure that, while all the participants have some idea of the nature of the proceedings involved, they are ignorant of the identities or contributions of all the other members of the conspiracy (Kutz 2000a passim). However, it seems plausible that the point has broader application, a matter of some significance for our current purposes. Historically documented instances of genocidal killings typically involve large numbers of perpetrators acting in ways that require the actions of different individuals to interlock in various mutually reinforcing ways. Successful campaigns of genocide require much more than the existence of a large class of individuals who are prepared to kill: killers must have access to weapons and food; victims must find themselves in a situation where possible avenues of escape have been cut off; individuals who might intervene need to be prevented or deterred from doing so. But actions of this sort can occur without requiring detailed central coordination. What is required in the absence of such co-ordination is just that individuals understand what they need to do on any given occasion in order to promote a certain overall goal and that they act accordingly. ${ }^{5}$ It is

${ }^{5}$ The Rwandan genocides of 1994 seem to fit this model well. See Gourevitch 2000. 
difficult to see how this sort of concerted action could be sustained over an extended period, in any realistic situation, without some sort of sense on the part of perpetrators that they are involved in a collective project, and without a desire to play their part in sustaining that collective project. (To this extent, it is perhaps unsurprising that mechanisms of national or tribal self-identification often seem to have played a role in enabling genocidal killing to take place.)

\section{Collective Wrongdoing and Collective Evil-doing}

If what I have said so far is correct, then actual instances of genocide do seem to fit Kutz's account of collective action. I now need to explain what role this fact might play in providing us with an illuminating and vindicatory explanation of the moral intuition whose existence I drew attention to at the start of the essay. My argument here will run as follows. I shall start by explaining why one might think that an appeal to the idea that genocide involves collective action should be able to explain any aspect of our intuitions about the peculiar evil of genocide. I shall then identify two constraints that explanations of this evil should meet. Finally I turn to the task of finding an account that meets those constraints.

In what follows, I shall use Kutz's views about collective wrongdoing as a useful starting point and object of comparison with the view I shall be developing. My account differs from Kutz's in various ways. The most obvious is that mine is an account with a slightly different target. Kutz is interested in the relatively broad issue of collective wrongdoing. But, as Card and others have argued, wrong and evil are not coextensive categories (Card 2001, Morton 2004). While it is plausible that all evildoing involves wrongful action, not all wrongful action involves the commission of evils. (One fairly uncontroversial difference between them is that wrongdoing can be trivial, while evil cannot.)

Perhaps unsurprisingly, Kutz's account does not provide us with a satisfactory account of the collective commission of evil. Nevertheless, it does contain one significant insight that will be important for the purposes of this essay. For it suggests an illuminating way of thinking about forms of wrongdoing whose wrongness seems to outrun anything that is easily accounted for by consideration of the wrongness of individual contributions to that wrongdoing. The key thought here is that once we take at all seriously the idea of collective wrongdoing involving distinctively collective action, we can locate some of the wrongness of the action not in the individual contributions to the wrongdoing but in the collective action as a whole.

If this is right, then what we need is an account that incorporates this insight of Kutz's, while being sensitive to the significant conceptual distinction between evil-doing and wrongdoing. Arguing for such an 
account will require us to say something about what that distinction amounts to; I shall turn to this task in due course. Nevertheless, and anticipating my ensuing discussion somewhat, I am now in a position to say something further about the difference between Kutz's general account of collective wrongdoing and my account of the peculiar evil of genocide. As we shall see in what follows, Kutz focuses his account on formal features of some of the maxims that he takes to be involved in some instances of collective action. By contrast, my account of the peculiar evil of genocide focuses on features of their content. More specifically, it relies on the idea that the collective action involved in genocidal killing involves disregard of and disrespect for the humanity of its victims.

\section{Kutz on Collective Wrongdoing}

I suggested earlier that Kutz's account of collective wrongdoing incorporated an insight that will play an important role in giving an account of the peculiar evil of genocide. That insight arises out of the idea that what makes some sorts of collective wrongdoing wrong may be features of the collective action that we might be inclined to overlook when focusing on the rightness or wrongness of individual contributions to that collective action.

The move that Kutz makes which is of interest here, and which enables him to go some way towards substantiating this line of thought, is to identify something that we can regard as a maxim of action, and thus something to which we can apply Kantian tests of universalisability and the like, without its being the maxim of any particular individual. We do this by considering the participatory intentions involved in the constitution of the collective action.

As Kutz argues, this suggestion gives an illuminating account of some cases of conspiratorial wrongdoing. Consider someone who is a getaway driver for a gang of armed robbers. Viewing the driver from a narrow perspective, we may find it difficult to explain why we should regard him or her as doing anything wrong. This will certainly be the case on certain sorts of Kantian account. What sorts of maxims might such an individual have that fail of universalisability? If we focus only on the actions involved in driving the getaway vehicle, it is difficult to see how any of them might involve a culpable maxim. But once we see him or her as a willing participant in a project of armed robbery, we can ask whether the maxims implicated in this project are ones that we can universalise. If not, then we can say that we have an instance of collective wrongdoing here. We can then go on to explain the culpability of the driver in terms of his or her willing participation in a collective action that is wrong.

Since Kutz's account deals well with the culpability of conspirators and indirect participants in crimes, one might well think that it is likely to have something to offer in the current context. One aspect of the debate 
over the responsibility of "ordinary Germans" for the Holocaust has been over whether we can regard those who did not participate directly in the slaughter of Jews as bearing any sort of responsibility for their fate. Kutz's account suggests one way in which they could be.

Nevertheless, Kutz's account is an account of collective wrongdoing, not collective evil. Since, as I have already suggested, not all wrongdoing involves evil, we should expect to find that a plausible account of collective evil-doing, in particular of the kind of evil whose presence in genocidal killing accounts for the intuition that this essay sets out to explain, will be subject to constraints that Kutz's own account does not need to satisfy.

One such constraint is fairly obvious. While it is no objection to an account of collective wrongdoing that it should entail that such wrongdoing might be relatively widespread (particularly in cases where large numbers of people participate in a collective project in ways that are relatively tangential), a view that aims at accounting for collective evildoing, in particular for some kind of peculiar evil, should not have such consequences.

This claim is not intended as an expression of moral complacency. The point is not that collective evil-doing could not have been widespread or that certain kinds of reflection might not help us to discern it in places where we might not previously have suspected it. It is rather that we are trying to find some sort of explanation for a distinction that we are inclined to make between, on the one hand, the sorts of serious wrongdoing involved in, say, our collective neglect of the environment and, on the other hand, something that is peculiar to genocidal killing. So an account that effaces that distinction is, to that extent, unsuccessful.

A second constraint, which is less obvious but equally important, relates to a point that has been importantly emphasised in recent work by Card (2001). Card convincingly argues that any account of evil needs to do justice to the moral significance of the suffering of the victims of that evil. She goes on to suggest that this rules out certain well-known accounts of wrongdoing, particularly Kantian ones, as plausible accounts of evil. This is because, in focusing on the nature of the will of the perpetrators of evil, they neglect the suffering of victims. While Card says nothing explicit about accounts of evil that locate evil in collective rather than individual willing, the point she makes about the moral significance of the suffering of victims seems applicable here as well, particularly given Kutz's stress on such paradigmatically Kantian considerations as the non-universalisability of maxims involved in collective wrongdoing.

\section{Genocidal Killing, Collective Action and Social Death}

Despite the ways in which Kutz's account of collective wrongdoing is unsatisfactory as an account of the peculiar evil of genocide, there seems 
at least some reason to think that a variant account might be more successful. Like Kutz's account, the account I have in mind focuses on features of the participatory intentions that are involved in the sort of collective action I have taken to be present in typical cases of genocidal killing. However, unlike Kutz's account of collective wrongdoing, which focuses on formal features of that collective willing, mine considers its content and the sorts of collective attitudes that we can take to be manifested by it, in particular the fact that this collective willing involves a deliberate, explicit and conscious lack of respect for the humanity of its victims.

For this line of argument to succeed, I need to do two things. The first is to show that the collective willing involved in genocidal killing does indeed have the features that I have attributed to it. The second is to show that the account that I have put forward meets the constraints that I have argued an account of collective evil-doing needs to meet. Once these two tasks have been completed I shall go on to address some objections to my account as a whole.

In arguing that the collective willing involved in genocidal killing does involve deliberate, explicit and conscious lack of respect for the humanity of its victims, I draw heavily on Card's suggestion that the notion of social death plays a central role in understanding the evil of genocide (Card 2003). More precisely, I claim that it is because genocidal killing involves participation in a collective project of inflicting social death on individuals that we can see that the collective willing involved in genocidal killing involves a lack of respect for its victims' humanity. Nevertheless, my view differs from Card's in a crucial respect. For Card, it is the nature of the harm that genocidal killing inflicts on its victims that is central to explaining the peculiar status of genocide. On my account, by contrast, what is significant is that the infliction of this harm is - in ways that I raised in section 4-a collective project.

Card introduces the notion of social death in the following terms:

When a group with its own cultural identity is destroyed, its survivors lose their cultural heritage and may even lose their intergenerational connections ... in that event they may become "socially dead" ... no longer able to pass along and build on the traditions, cultural developments and projects of earlier generations. $(2003,73)$

As this passage suggests, and as Card emphasises, although social death results from the destruction of communities, it is to be conceived of as a harm inflicted not on communities themselves but on individuals who make up those communities, or who would have done so had those communities survived intact. ${ }^{6}$

\footnotetext{
${ }^{6}$ Card's understanding of this notion strikes me as importantly different form that of Orlando Patterson, whom she cites in this context. See, for example, Patterson 1982, 39-45.
} 
I take the notion of social death to be important in this context for the following reason. Earlier I argued that genocidal killing involved collective action. I now want to argue that it involves collective participation in a project of inflicting social death on its victims, and that as such it involves disregard for their humanity.

In order to establish the first of these claims, I need to do more than simply show, as Card aims to, that survivors of genocide typically suffer social death, and that this is inflicted in a culpable manner. These claims could be true if the suffering of cultural death was merely an unintended consequence of such killing. For the claim that I am making to be true, the notion of social death needs to figure in the participatory intentions of the individuals involved in genocidal killing.

It is highly plausible that some such notion has played an important role in the planning and execution of many paradigmatic examples of genocidal projects. Such projects have aimed not only at the destruction of a group of individuals falling into a certain class but also at the destruction of the very conditions of the possibility of there being individuals who fall into that class. So, for example, the Nazis' destruction of European Jewry had the goal not simply of exterminating large numbers of Jews but also of wiping the Jewish people from the pages of history (Goldhagen 1996). Something similar seems to be true of the genocidal killing that took place in Rwanda in 1994. Part of the point of this killing was not simply to destroy those Tutsis who were in Rwanda; it was to destroy the possibility of being a Tutsi in Rwanda (Gourevitch 2000). (Card's remark that genocide targets people because of who they are seems apposite in this context; but one might go even further and say that genocide targets not only individuals but also who they are, the very possibility of bearing a particular kind of identity.)

One might wonder, nevertheless, whether what is true of these paradigmatic cases is true in all cases. One particularly problematic case concerns the suffering of Native American peoples in both North and South America at the hands of European invaders. It is plausible to claim that much of the cultural destruction that occurred as Europeans took possession of territory in the Americas occurred as the unforeseen consequence of otherwise culpable actions. For example, it is clear that huge falls in the indigenous populations of Central America during the Spanish conquest were the result of the introduction of microbially transmitted disease, a process of which the invaders had no understanding. It also seems likely that in some cases the destruction of indigenous populations was experienced as a frustrating problem by invaders, especially in so far as it deprived them of a source of easily exploitable slave labour (Stannard 1991).

On Card's account, such facts as these present no obstacle to classifying the actions of early European settlers in America as genocidal. For it is clear that although those individuals had no understanding of the 
consequences of their actions, they acted culpably in various respects, and in acting culpably they inflicted the intolerable harm of social death on their victims, even if they had no understanding of the nature of the harm they were inflicting or the mechanisms by which that harm was inflicted, and even if, in some cases, this may have run counter to their actual intentions (Card 2003, 73). By contrast, it is less obvious whether on my account these actions did involve the peculiar evil of genocide. For it might be thought that such facts as these show that, although the destruction of indigenous peoples in the Americas may have involved collective projects of various sorts (for a project of invasion must certainly do so), the infliction of social death need not have figured among them.

Nevertheless, I think that matters are not so clear-cut as this suggests. For, as David Stannard documents, and at least some contemporary sources testify, there is a strong case for thinking that the destruction of Central and South American civilisations by European invaders involved not just disease and mistreatment but also the deliberate destruction of the cultural resources on which their way of life depended, all of which was facilitated by a religiously fuelled ideology that regarded the members of those civilizations as less than fully human, and their way of life as being of no value. If this is correct, there is a good case for thinking that the invaders were engaged in a collective project that aimed at the infliction of social death, and that this collective project involved a lack of respect for-underpinned by an ideological lack of belief in-the humanity of its victims.

\section{Social Death and Disregard for Humanity}

I have now argued that the collective action involved in genocidal killing involves a project of inflicting social, not merely physical, death on its victims. Earlier I claimed that in so far as it does so it involves conscious disrespect of their humanity. This point may seem either otiose or inapposite. One reaction to it might be to say that what is significant about social death in this context is that it is an intolerable harm, suffered by victims. On this view, we need to go no further than pointing to this harm, and the fact that it is intolerable, in explaining the peculiar evil of genocide. A second reaction might be that talking of "respect for humanity" in this context is beside the point. For this phrase, with its Kantian overtones, is apt to suggest that what is involved here is a lack of respect for individuals' rational capacities; and it might well be said that the harms inflicted on individuals who suffer social death go further, and deeper, than their rational nature.

However, while both these reactions are understandable, neither is quite correct. To explain why not, I shall have to say more about what I take the notion of humanity, and respect for it, to entail, and something about the role it plays in my argument. I shall start by saying something 
about the relationship between rationality and humanity. One point that may be worth making is that even within a Kantian framework there is room for making a distinction between these notions. For Kant, one thing that distinguishes human rationality from rationality as such is that the former is, while the latter need not be, embodied rationality.

Putting the point as abstractly as this leaves indeterminate what might be constitutive of embodied rationality. For Kant, what is significant is that the human will is capable of being determined by what he calls "sensuous impulses" - which he regards both as a limitation on our moral natures and as something that, because it is a precondition of there being any imperatives at all, is a precondition of the possibility of moral imperatives, and hence of our being moral beings at all (Kant 1993, 23-25). But we need not follow Kant at this point. For we might also think that it is characteristic of actual human beings' rational natures, if not of rationality conceived of in the abstract (what we might, perhaps misleadingly, describe as "rationality as such"), that these natures should be embodied in and sustained by traditions, cultural institutions and practices that are sustained across generations.

In talking of such traditions, I am talking less of what one might describe as "high culture" and rather in terms of low-level institutions, such as counting systems, stories told to children, ways of growing and preparing food, moral and social codes expressed in day-to-day behaviour and the like. These are precisely the sorts of things that individuals who suffer from social death, under Card's understanding of it, are deprived of. To that extent, we can talk of the infliction of social death on individuals as involving disregard of and disrespect for their embodied rationality, and hence for their humanity. We can also see one line of thought that might help to account for Card's important, but somewhat under-explained, claim that to suffer social death may be as bad as to suffer physical death (Card 2003, 73).

We are now in a position to see the role that appeal to this notion of humanity as embodied rationality plays in my account of the peculiar evil of genocide. The notion is significant for two reasons. First, it allows us to flesh out the claim that genocide involves evil-doing. As I have already observed, Card characterises evil as "intolerable harm, culpably inflicted" (Card 2001, 3-5; Card 2003, 66; Card 2004, 216). No one would deny, I think, that on this account genocidal killing involves the infliction of evil. Nevertheless, as Adam Morton has suggested, the notion of something's being "intolerable" that Card appeals to here is a normatively loaded one: it refers to what we should not tolerate, rather than what we cannot tolerate (Morton 2004, 199). And in so far as our aim is not to defend the claim that genocidal killing is evil (since that is not in dispute) but rather to have a better understanding of what that claim is, we might be inclined to ask what it is about the kind of harm involved in the infliction of social death that makes it intolerable. Part of the answer to 
this question is provided by pointing to the ways in which it involves the destruction of humanity, not just of human beings.

Furthermore, and relatedly, appeal to the notion of disrespect for humanity as embodied rationality helps us to address the issue with which this essay is primarily concerned: that of explaining the peculiar evil of genocide. For, while it may be the case that some intolerable harms are intolerable because they involve disrespect for and disregard of the humanity of their victims, it is not clear that all are. There are some harms that we should not tolerate because they involve such disrespect. There are others that we should not tolerate because of the magnitude of the suffering involved, or its pointlessness, or the cruelty involved in inflicting it.

\section{Is the Account Too Complex?}

My explanation of our moral intuition of the collective evil of genocide has been that this intuition represents a rational response to the disregard for humanity (or embodied rationality) expressed in the collective willing that is typically to be found in cases of genocidal killing. Thus it appeals to two different aspects of genocidal killing. It is natural to wonder whether a simpler account appealing to only one of these features would be preferable.

I addressed some aspects of this question in section 6. There I argued that an account of the peculiar evil of genocide that appealed only to the fact that genocidal killing involved collective wrongdoing would be unsatisfactory, at least in part because it would not address what was peculiarly evil about genocide, or indeed why we should see genocide as evil at all, rather than merely wrong. While arguing for that view, I identified two constraints that an adequate account of this evil needed to meet.

The first constraint was that an account of the peculiar evil of genocide needed to appeal to some feature of the genocidal killing that was not so widespread as to make it the case that the evil of genocidal killing was commonplace. To propose an account that did not meet this constraint would have been to reject the terms in which the guiding question of this essay is posed. Kutz's account of collective wrongdoing, which appealed to the non-universalisability of a maxim present in the collective willing of a group of individuals, did not satisfy this constraint, precisely to the extent that it succeeded as a more general account of collective wrongdoing. However, the account that I developed in the previous two sections does satisfy it. For it is not true that all collective wrongdoing involves disregard for the embodied rationality of its victims. For example, collective wrongdoing that involves destruction of wilderness environments or the infliction of unjust but not intolerable inequalities would not have this feature. 
The second constraint was, in effect, that the account needed to do justice to the moral significance of the suffering of victims of genocide. I argued that Kutz's account of collective wrongdoing was unlikely to meet this constraint in view of its strongly Kantian aspects. Nevertheless, one might wonder whether the account I have put forward, which also stresses the nature of the collective willing involved in acts of genocide, is any more successful, particularly given that it has its own Kantian resonances.

Before I address this issue, however, it may be worth saying a bit more about Card's position. She holds that there is something wrong with accounts of evil that do not make reference to the suffering of individuals who are the victims of that evil. However, she does not take it to be a constraint on a plausible account of evil that it should make no reference to the will of the perpetrator. Rather, the suggestion is that an adequate account of evil should make reference to both. (Card's own view accommodates this by defining evil in terms of the culpable infliction of intolerable harm on victims and allowing for will-related conditions to contribute to an account of culpability.)

It is clear that the account I have put forward of the peculiar evil of genocide makes reference to the collective willing of perpetrators. In doing so it also makes reference to their individual willing: this is ensured by Kutz's metaphysically lightweight account of collective action. The only question that remains to be addressed is whether my account grants sufficient moral significance to the suffering of victims. The answer to this is yes. Notice that the feature of the collective willing involved in acts of genocide that explains the peculiar evil of genocide consists in a relationship between the willing of perpetrators and the suffering of victims. This contrasts significantly with Kutz's account of collective wrongdoing: on that account, the suffering of victims seems irrelevant to explaining a collective action's status as a collective wrongdoing.

One might doubt this on the grounds that we can conceive of cases in which there is the sort of collective willing that I take to be constitutive of the peculiar evil of genocide, but without any actual suffering taking place-for example, among a group of ineffectual and witless conspirators. I want to make two points about such cases. First, it is not obvious that it is a disadvantage of my view that it allows for ineffectual evil provided that there are good grounds for taking the possibility to be marginal. Second, we do have such grounds, on my account. Given my stress on the role of participatory intentions and what they must manifest, it is very difficult to flesh out the possibility of collective action of the requisite sort that does not involve inflicting actual evil. It is hard to have participatory intentions that refer to an entirely unrealized project.

This completes the task of showing that an account of the peculiar evil of genocide that incorporates the notion of collective willing embodying disrespect for embodied rationality is superior to one formulated simply in terms of collective wrongdoing. But one might equally wonder whether 
reference to collective willing is necessary at all. One reason for thinking so, which I alluded to earlier, lies in the idea that the fact that the evil of genocide is located in features of collective rather than individual action could help us to explain why it is so difficult to give an account of that evil. For we are often inclined to forget the collective dimensions of action in giving an account of what is morally significant.

This argument can only be successful, however, if all other candidate views are unsuccessful. To make a plausible case for this, I must at least address Card's view that the peculiar evil of genocide can be accounted for not by reference to the sort of collective action that perpetrators of genocide undertake but simply by reference to the idea that it involves the culpable infliction of social death. My main difference from Card on this point arises from the fact that it is possible for individuals to inflict social death on others in ways that are not genocidal and, atrocious as they are, do not involve the peculiar evil of genocide.

The sorts of case I have in mind here are cases involving extreme and long-term neglect of young children over periods of time that makes it impossible for them to acquire the linguistic abilities of normal human beings. (It is perhaps worth emphasising that we are talking about actual and tragic cases here, and not the sort of morally offensive science fiction whose relevance I dismissed earlier on.) It seems plausible that such individuals are, in Card's words, "no longer able to pass along and build on the traditions, cultural developments and projects of earlier generations." To that extent they seem to fit Card's characterisation of social death. It also seems plausible to think that their treatment involves disregard of and disrespect for their embodied rationality. Furthermore, in many cases the harm that these individuals suffer will have been culpably inflicted.

On Card's account it seems hard to deny that individuals in this situation have suffered the same sort of evil as survivors of genocide. (Notice that this point depends on Card's characterisation of social death as a harm suffered by individuals.) Indeed, in so far as the inability of such individuals to engage in cultural projects of any sort goes deeper, in some ways, than that of genocide survivors (for these individuals have no capacity to engage in any attempt at a project of cultural recovery), their situation seems worse. While this cannot be described as a refutation of Card's view, it strikes me as a significant drawback. For we might well have hoped that an account of the peculiar evil of genocide would isolate something unique to genocidal killing.

One advantage of the account that I have put forward is that it does seem to allow us to draw a distinction here. For it is not obvious that this sort of treatment of children need involve collective action; it may simply involve individuals acting cruelly and negligently. There may also be cases where it does involve collective action: for example, where the neglect is institutionalised, as in some orphanages in some of the formerly 
communist countries of Eastern Europe. But these sorts of cases seem to shade into ones that Card would want to characterise as analogous to genocide, such as the forcible destruction of the cultural ties of very young children by fostering them in alien cultures.

Bilkent University

06800 Bilkent

Ankara

Turkey

wringe@bilkent.edu.tr

\section{References}

Card, C. 2001. The Atrocity Paradigm. Oxford: Oxford University Press. 2003. "Genocide and Social Death." Hypatia 18, no. 3 (winter): 63-79.

_. 2004. "The Atrocity Paradigm Revisited." Hypatia 19, no. 4 (fall): $210-20$.

French, P. 1984. Collective and Corporate Responsibility. New York: Columbia University Press.

Gilbert, M. 1989. On Social Facts. London: Routledge.

- 2000. Sociality and Responsibility: New Essays in Plural Subject Theory. Lanham, Md.: Rowman and Littlefield.

Goldhagen, D. 1996. Hitler's Willing Executioners: Ordinary Germans and the Holocaust. London: Little, Brown.

Gourevitch, P. 2000. We Wish to Inform You That Tomorrrow We Will Be Killed with Our Families. London: Picador.

Kant, I. 1993. Grounding for the Metaphysics of Morals. Translated by James W. Ellington. Third edition. Indianapolis: Hackett. Originally published in 1785 .

Kutz, C. 2000a. Complicity: Law and Ethics for a Collective Age. New York: Cambridge University Press.

- 2000b. "Acting Together." Philosophy and Phenomenological Research 61:1-31.

Morton, A. 2003. On Evil. London: Routledge.

—. 2004. "Inequity/Iniquity: Card on Balancing Injustice and Evil." Hypatia 19, no. 4:197-202.

Roth, P. 2004. "Hearts of Darkness: Perpetrator History, and Why There Is No Why." History of the Human Sciences 17, nos. 2-3:211-51.

Stannard, D. 1991. American Holocaust. Honolulu: University of Hawaii Press.

Wiggins, D. 1987. "Truth, and Truth as Predicated of Moral Judgments." In Needs, Values, Truth, 139-85. Oxford: Oxford University Press. 